\title{
A STUDY ON SEDIMENTATION OF TIDAL RIVERS AND CHANNELS FLOWING INTO DEEP BAY WITH A DELFT3D MODEL
}

\author{
Z.B. WANG \\ Deltares \& Delft University of Technology, Faculty of Civil Engineering and \\ Geosciences, P.O. Box 177, 2600 MH Delft, The Netherlands \\ M.L. TSE \\ Mott MacDonald Hong Kong Limited, Hong Kong \\ S.C. LAU \\ Drainage Services Department (DSD), Government of the Hong Kong SAR
}

\begin{abstract}
For supporting Drainage Services Department of the Government of the Hong Kong SAR to develop a comprehensive strategy for overall land drainage and flood control in Yuen Long and North Districts, 3D hydrodynamic and sediment transport model is set up. The model deploys Domain Decomposition technique and covers the whole Deep Bay (the estuary of the Shenzhen River), the tidal sections of the rivers and drainage channels including Shenzhen River, Kam Tin River, Shan Pui River and Tin Shui Wai Main Drainage Channel flowing into Deep Bay and a part of the Pearl Estuary. As driving forces, the model takes into account waves and flow driven by wind, tide, river discharge and salt intrusion. Field surveys for wind waves, sediment concentration and especially sediment properties have been conducted. The collected data are analysed together with the existing data and used as basis for the set up of the model. The model is calibrated especially against the development of sedimentation in the Lower Shenzhen River since 2000, after a major deepening of the river. The model can be applied to predict sedimentation in Shenzhen River and tidal drainage channels for different scenarios concerning dredging strategy and river discharge regimes. The study has improved insights into the complicated hydrodynamic and morphodynamic system of Deep Bay together with the rivers and channels flowing into it.
\end{abstract}

\section{Introduction}

Drainage Services Department of the Government of the Hong Kong Special Administrative Region (SAR) is developing a comprehensive strategy for overall land drainage and flood control in Yuen Long and North Districts. For this purpose Mott Macdonald Hong Kong Limited and Deltares from the Netherlands 
are commissioned to carry out a Review Study for the previous Drainage Master Plan Studies for the Yuen Long, Kam Tin, Ngau Tam Mei and Tin Shui Wai Drainage Basin (YLDMP) and the Northern New Territories (NNTDMP), see Figure 1.

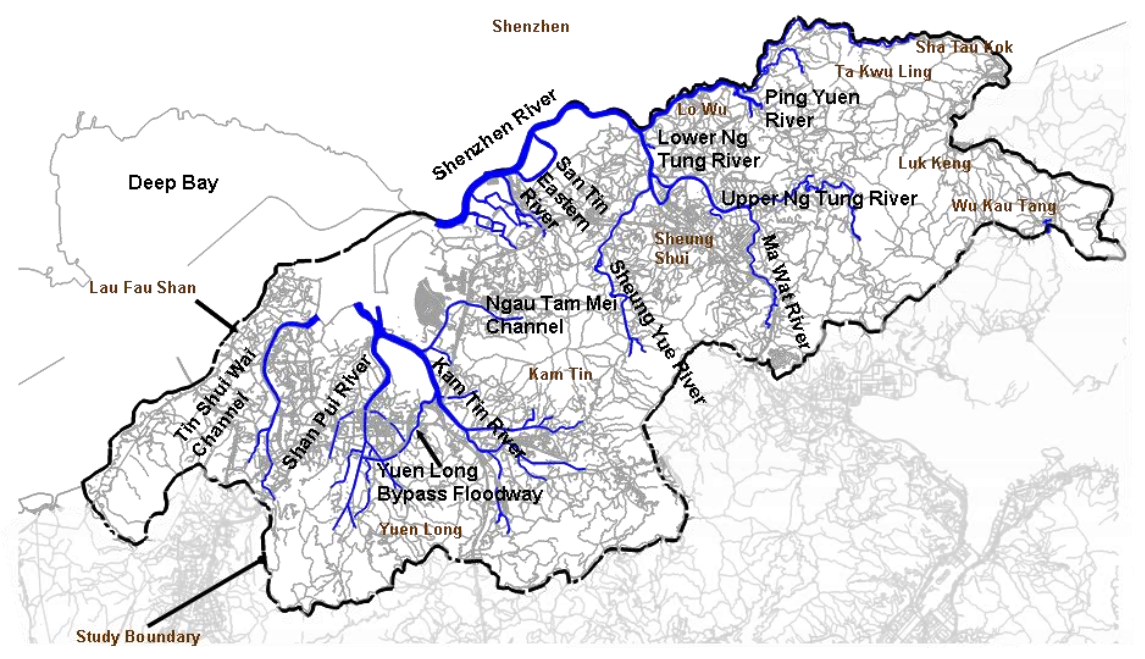

Figure 1. Study area.

An important issue in this study is the sedimentation in the tidal sections of the rivers and drainage channels which may cause serious problems for flood control. This sedimentation issue is studied with the help of a three-dimensional (3D) hydrodynamic and sediment transport model based on the Delft3D modelling system of Deltares.

\section{Modeling approach}

The sediment modeling to be carried out is meant to obtain more understanding of and insight into the sediment transport and morphological development of the Deep Bay-estuaries-rivers system, and to quantify the sedimentation amount in the bay and in the estuaries/tidal sections of the river channels. For this purpose, it is important to reproduce all the relevant mechanisms for sediment exchange between the Pearl River Estuary and Deep Bay, and between Deep Bay and the estuaries of the rivers. This also requires one to take into account all the relevant physical processes influencing transport, deposition and erosion of sediment using correct formulations.

Based on the results of former studies for the same area and after analyzing the available data, it is concluded that the model to be set up should have the following features: 
1. The seaward open boundary should not be located exactly at the mouth of Deep Bay. It shall be extended to include a part of the Pearl River Estuary. This makes it possible that the circulation flow in the outer part of the bay driven by the flow in the Pearl River Estuary can be simulated as this circulation is important for water and sediment exchange between the Pearl River Estuary and Deep Bay;

2. As gravitational circulation is an important mechanism for residual sediment transport in an estuary, a 3-dimensional model, including salinity, should be applied; and

3. Influence of wind waves has to be taken explicitly into account as wave action in the bay can play an important role by stirring up sediment influencing the sediment transport from the bay to the tidal sections of the drainage channels and the river estuaries.

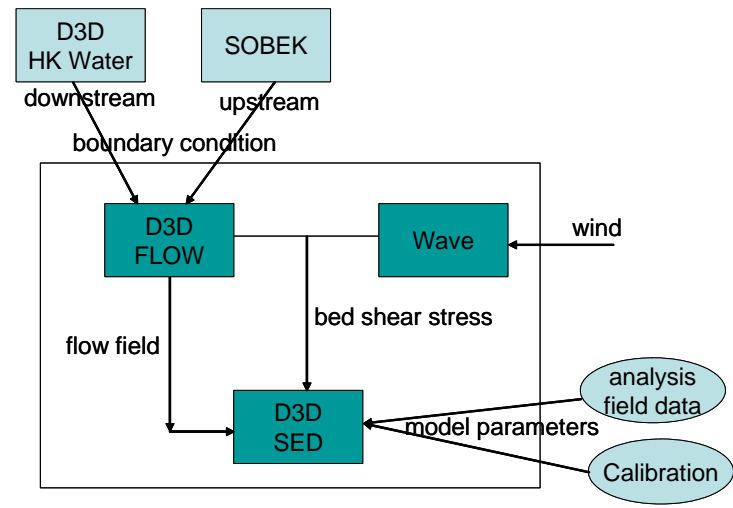

Figure 2. Modeling approach.

Figure 2 illustrates the applied modeling approach. The model consists of three modules, a 3D flow module, a wave module and a sediment transport module. The wave module calculates the wind wave field based on wind speed and fetch length. The flow module and sediment transport module are described in more detail in the following.

\section{Hydrodynamic model}

The hydrodynamic model covers Shenzhen River, Yuen Long River, Deep Bay area and a part of the Pearl River Estuary connecting to Deep Bay. The model uses the hydrodynamic simulation program Delft3D-Flow [4] to compute water levels, flow velocities and salinities. The model grid consists of 4 separate domains. The resulting grid layout is shown in Figure 3. Domain decomposition in combination with curvi-linear grids is employed in order to properly represent the channels in the inner Deep Bay area using acceptable number of grid points. 
In the vertical direction 10 sigma-layers, each having a thickness of $10 \%$ of the local water depth, are used.

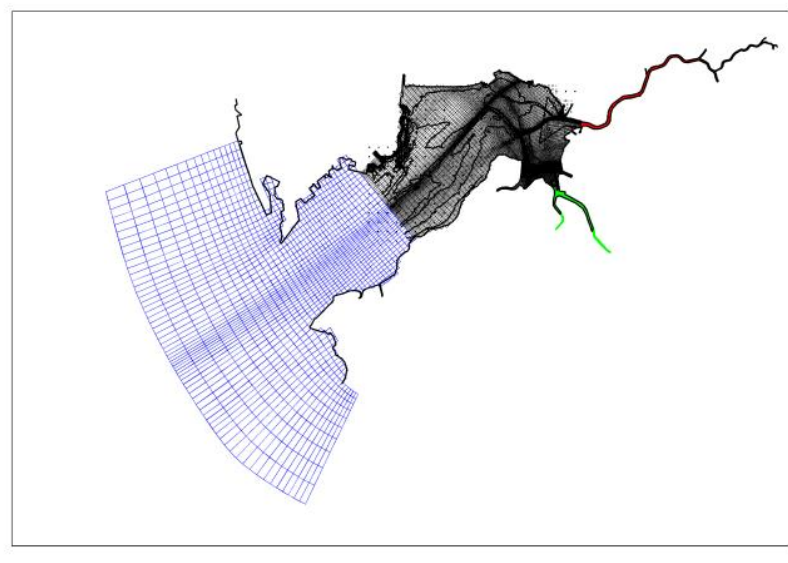

Figure 3. Model grid.

The boundary conditions are generated by two other models as illustrated in Figure 2. At the river boundaries discharges generated from a SOBEK model covering the whole catchment of Deep Bay are prescribed. SOBEK is the 1D river network modeling system of Deltares. The open sea boundary conditions are generated by a larger scale Delft3D model (Pearl Estuary model). This model covers the entire Pearl Estuary, the Hong Kong Waters and a coastal stretch in front of Pearl Estuary. The model is forced by water levels generated from this Pearl Estuary model at the northern and southern model boundary. For each of the 10 computational layers of the Deep Bay model, time series of salinity as computed with the Pearl Estuary model are prescribed as boundary condition at the northern and southern Deep Bay model boundary.

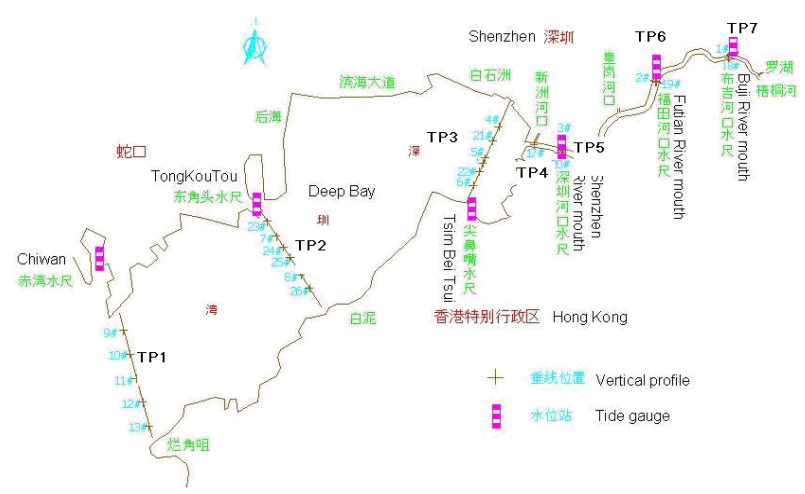

Figure 4. Overview of stations. 
Wind impacts are included in the model by applying a constant wind speed and direction representative for average dry and wet season conditions. For the dry season simulations, a wind of $5 \mathrm{~m} / \mathrm{s}$ directed from the north-east is used. For wet season simulations, a south-westerly wind of $5 \mathrm{~m} / \mathrm{s}$ is applied in the model.

The hydrodynamic model is calibrated and verified using field data collected in October 2004 (dry season) and June 2005 (wet season) [2]. Both campaign measurements of flow velocity and salinity have been carried out during the spring tide and neap tide. Figure 4 shows an overview of measurement stations for various parameters.

\section{Sediment transport model}

The sediment transport model is set up using Delft3D-Sed. It simulates the 3D suspended sediment concentration field on the basis of the 3D flow field supplied by the hydrodynamic model. Deposition and erosion are taken into account for the sediment exchange between water column and the bottom:

$$
\begin{array}{ll}
D=w_{s} c_{b} & \\
E=M\left(\frac{\tau}{\tau_{c}}-1\right) & \text { for } \tau>\tau_{c} \\
E=0 & \text { for } \tau \leq \tau_{c}
\end{array}
$$

where

$$
\begin{aligned}
D & =\text { deposition rate } \\
w_{s} & =\text { settling velocity } \\
c_{b} & =\text { sediment concentration in the lowest layer } \\
E & =\text { erosion rate } \\
M & =\text { erosion coefficient } \\
-\quad & \text { bed shear stress } \\
-c & =\text { critical bed shear stress for erosion }
\end{aligned}
$$

The bed shear stress used for calculating the erosion rate depends on flow velocity as well as wave parameters (Figure 2).

The three model parameters, settling velocity, erosion coefficient and the critical shear stress are first estimated by data from bottom sample analysis. Bottom samples were collected from the field and analyzed in laboratories to determine a series of parameters indicating the physical-chemical properties of the sediment. These parameters are then used to calculate the three model parameters according to the theory of Winterwerp and Van Kesteren [1]. The settling velocity can also be estimated by analyzing the measured sediment concentration verticals. The two methods lead to the same results, viz. the settling velocity is about $0.3 \mathrm{~mm} / \mathrm{s}$. In the model, the sediment is divided into two 
fractions, the fine fraction with $w_{s}=0.1 \mathrm{~mm} / \mathrm{s}$ and a coarse fraction with $w_{s}=0.5$ $\mathrm{mm} / \mathrm{s}$. The remaining two parameters in the erosion formulation are further finetuned during the calibration of the model.

The driving forces influencing the sediment transport and morphological changes include river discharge, sediment input from rivers, tide, wind, sediment concentration outside Deep Bay, etc. The variation of the tide and the seasonal variation are more or less deterministic, whereas the wind and the specific river flood events are typically stochastic. Simulations of two different situations are carried out: the dry season situation and wet season situation. The sedimentation rate for the dry season is determined by simulating a spring-neap tidal cycle, with constant river discharges. The wet season simulations use the same representative spring-neap tidal cycle, but the river discharge is time varying and representing the river discharge regime of the wet season in a particular year. The annual sedimentation rate is determined as the sum of the sedimentation amounts during the two schematized periods, together covering a complete representative year.

As boundary conditions, the sediment concentrations at the upstream river boundary as well as at the open sea boundary need to be prescribed. For the dry season, constant values are used for the concentrations at the boundaries. For the wet season, the sediment concentration depends on the river discharge as follows [3]:-

$$
c=a Q^{b}
$$

where

$$
\begin{aligned}
c & =\text { Sediment concentration }\left(\mathrm{g} / \mathrm{m}^{3}\right) \\
a & =\text { Coefficient } \\
Q & =\text { Discharge }\left(\mathrm{m}^{3} / \mathrm{s}\right) \\
b & =\text { Coefficient }
\end{aligned}
$$

The two coefficients ( $a$ and $b$ ) in this equation are determined for each river in the model based on field data.

The model is calibrated against two types of field data, viz. sediment concentration field and morphological change data. As the model is eventually meant for predicting sedimentation rate in the tidal sections of the rivers and drainage channels, emphasis of the calibration is paid to the morphological change. Therefore, only a representing spring-neap cycle for the dry and the wet season has been simulated for each particular year. The measured and simulated sediment concentrations are compared by looking at their characteristics of the spatial and temporal variations.

Figure 5 shows an example of the comparison between the observed and computed variation of the sediment concentration along Deep Bay and Shenzhen 
River. The lines depict the transect-averaged values and the dots show the values at all the verticals at a transect. The characteristics of the sediment concentration fields measured in 2004-2005 campaigns are well reproduced by the model with the parameter setting $M=0.03 \mathrm{~g} /\left(\mathrm{m}^{2} \mathrm{~s}\right)$ and ${ }_{\rightarrow c}=0.1 \mathrm{~Pa}$.

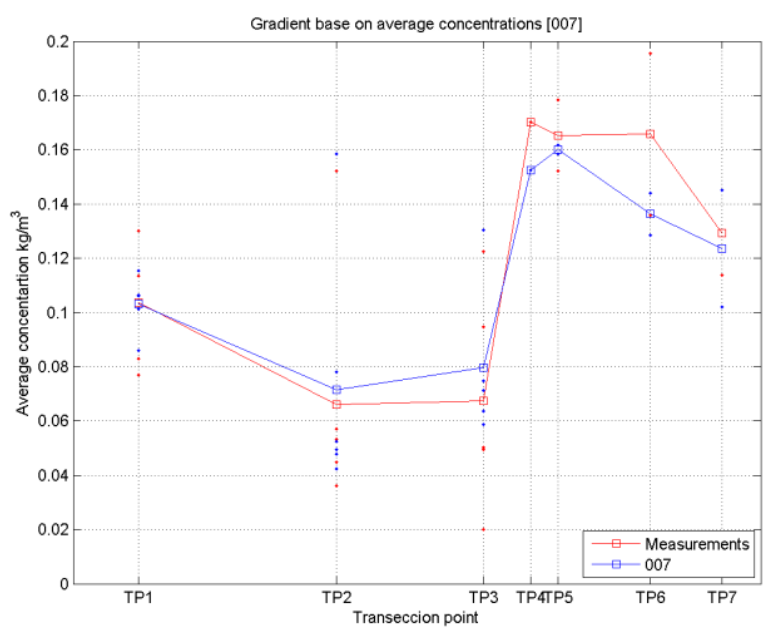

Figure 5. Variation of sediment concentration along Deep Bay and Shenzhen River derived from observation data and model simulation for 2005, wet season. Location of the Transect Points (TP) are indicated in Figure 4.

Concerning the morphological change, the bathymetric survey data and dredging records of Shenzhen River have been collected for the period 20012010. Due to a deepening by dredging in the section between the river mouth and Lo $\mathrm{Wu}$, serious sedimentation took place between 2001 and 2004. After 2004, the sedimentation slowed down significantly. Therefore, 2002 and 2005 have been selected for the calibration of the model. The sedimentation in 2002 was more than half million $\mathrm{m}^{3}$, whereas in 2005, no significant sedimentation or erosion took place. The calculated sedimentation amounts for the two years are given in Table 1. In addition to the run with the model parameters producing the best agreement with the observed sediment concentration field, the results of a run with doubled erosion coefficient are also given in the table, because they show much better agreement with the observations. Apparently, the sediment concentration in 2002 was much higher than that in 2005. In fact, with the sediment concentration level as observed in 2005, the high sedimentation amount as observed in 2002 could not be reproduced even if in the whole river section no erosion and only deposition would take place all the time. This indicates that the sediment concentration level in the system has been lowered since 2004, because of some unknown factors such as the developments alongside Shenzhen River, local dredging works etc. 
Table 1. Calculated total sedimentation amounts for the two years.

\begin{tabular}{ccccc}
\hline Year & \multicolumn{2}{c}{$\mathbf{2 0 0 5}$} & \multicolumn{2}{c}{$\mathbf{2 0 0 2}$} \\
$\mathrm{M}=$ & $0.03 \mathrm{~g} /\left(\mathrm{m}^{2} \mathrm{~s}\right)$ & $0.06 \mathrm{~g} /\left(\mathrm{m}^{2} \mathrm{~s}\right)$ & $0.03 \mathrm{~g} /\left(\mathrm{m}^{2} \mathrm{~s}\right)$ & $0.06 \mathrm{~g} /\left(\mathrm{m}^{2} \mathrm{~s}\right)$ \\
\hline Dry season $\left(\mathrm{m}^{3}\right)$ & 29,300 & 52,800 & 96,100 & 193,400 \\
Wet season $\left(\mathrm{m}^{3}\right)$ & 15,700 & $-96,500$ & 217,000 & 304,300 \\
Total in the year $\left(\mathrm{m}^{3}\right)$ & 45,000 & $-43,700$ & 313,200 & 497,700 \\
\hline
\end{tabular}

\section{Conclusions}

A three-dimensional hydrodynamic and sediment transport model for the Deep Bay and the rivers and drainage channels flowing into Deep Bay has been set up with the Delft3D modeling system. The model can be used for evaluating measures such as different strategies for maintenance dredging in the rivers for improving flood control. The results of the sediment transport model reveal that the sediment concentration level in the system has become lower since 2004. It is not clear what developments have caused this change. With the present sediment concentration level the model shows that the Shenzhen River is in dynamic equilibrium in agreement with the field observations [2].

\section{References}

1. Winterwerp, J.C. and Van Kesteren, W.G.M., 2004, Introduction to the physics of cohesive sediment in the marine environment, Elsevier, Developments in Sedimentology, Vol 56.

2. Yangtze Institute of Survey, Planning, Design and Research and Black Veatch Hong Kong Limited, 2008, Study to improvement and sedimentation of Shenzhen River (in Chinese), Report to Drainage Service Department, Hong Kong Government.

3. Hyder Consulting Limited, 1997, Territory land drainage \& flood control strategy study - phase III sedimentation study, Report to Drainage Service Department, Hong Kong Government.

4. Lesser, G.R., Roelvink, J.A., van Kester, J.A.T.M., Stelling, G.S., 2004. Development and validation of a three-dimensional morphological model. Coast. Eng. 51, 883-915. 